\title{
Komputasi Solusi Transien Rangkaian Listrik dengan GGL Gayut Waktu dengan Sistem Aljabar Komputer REDUCE
}

\author{
Arief Hermanto \\ Jurusan Fisika, FMIPA, Universitas Gadjah Mada \\ Sekip Utara, Yogyakarta \\ arief_hermanto@ugm.ac.id
}

\begin{abstract}
Abstrak - Dalam kebanyakan buku ajar solusi keadaan transien dari rangkaian listrik dengan ggl gayut waktu sembarang tidak pernah dibahas. Makalah ini berusaha mengisi kekosongan itu dengan menentukan solusi transien itu dengan bantuan sistem aljabar komputer atau bahasa pemrograman simbolik REDUCE. Program yang berhasil disusun ternyata sangat pendek dan menghasilkan keluaran (simbolik) yang sangat mudah dibaca.
\end{abstract}

Kata kunci: rangkaian listrik, komputasi, REDUCE

Abstract - In most textbooks the solution of transient state of electric circuit with arbitrary time dependent emf has never been discussed. This paper is an effort just to fill that gap to determine the transient solution with the help of Computer Algebra System (CAS) or symbolic programming language REDUCE. The resulting program proves to be truly compact and deliver (symbolic) result which can be read conveniently.

Key words: electric circuit, computation, REDUCE

\section{PENDAHULUAN}

Dalam pengajaran elektromagnetisme di perguruan tinggi selalu dijumpai pembicaraan mengenai rangkaian listrik karena topik ini jelas mempunyai aplikasi yang sangat luas. Mulai dari karya klasik tentang listrik statik dan dinamik [1], yang lebih modern [2] dan karya masa kini [3] tentang metode matematika dalam fisika dan keteknikan, semuanya selalu membahas rangkaian listrik karena di samping sangat intuitif dan luas aplikasinya, juga (dari segi matematik) bersifat isomorfik dengan sistem mekanik.

Ketika sampai pada pembahasan yang menyangkut ggl (gaya gerak listrik) gayut waktu biasanya penjelasan dibatasi hanya pada ggl yang sinusoidal dan pada saat sistem sudah mencapai keadaan ajeg, yaitu lama setelah ditutupnya saklar pada rangkaian listrik itu. Pada saat membahas keadaan transien, yaitu pada saat-saat yang dekat dengan ditutupnya saklar, biasanya digunakan ggl yang konstan atau ggl yang dihubung pendek [4].

Dalam makalah ini kita akan menentukan solusi ketika sistem dalam keadaan transien dengan ggl yang gayut waktu secara sembarang. Penyelesaian akan dilakukan secara komputatif dengan pemrograman simbolik menggunakan bahasa REDUCE. Penggunaan pemrograman simbolik (yang sering disebut sebagai Sistem Aljabar Komputer [Computer Algebra System = CAS]) memang sebaiknya mulai diperkenalkan sedini mungkin dalam pendidikan bagi calon fisikawan [5]. Bahasa REDUCE bukanlah satusatunya bahasa pemrograman simbolik, bahkan ada bahasa lain yang mempunyai kemampuan hanya sebagian dari keseluruhan yang biasanya dimiliki bahasa yang simbolik dan dapat digunakan dalam konteks tertentu, misalnya bahasa UBASIC [6]. Namun sebagai bahasa pemrograman simbolik yang sepenuhnya, REDUCE merupakan bahasa yang kami pilih karena berbagai keunggulannya.

\section{METODE DERET}

Sistem yang ditinjau adalah berupa rangkaian listrik yang terdiri atas beberapa lingkaran arus (current loop). Dalam setiap lingkaran itu variabel yang bisa digunakan adalah muatan (yang berada dalam kapasitor) dan arus listrik (yang melalui induktor dan resistor) dengan hubungan

(1)

$$
I=d Q / d t
$$

Misalnya terdapat $n$ lingkaran, maka dengan menggunakan hukum-hukum Kirchhoff akan dapat diperoleh

$$
\frac{d^{2} Q_{k}}{d t^{2}}=f\left(\frac{d Q_{l}}{d t}, Q_{l}, t\right), k, l=1 \ldots n
$$

(2) dengan $f$ merupakan fungsi linear.

Untuk memudahkan pembahasan di sini akan dibahas satu lingkaran saja sehingga kita peroleh

$$
\frac{d^{2} Q}{d t^{2}}=A \frac{d Q}{d t}+B Q+C \varepsilon(\mathrm{t})
$$

(3) dengan $\varepsilon(t)$ menyatakan ggl yang gayut waktu. Untuk kasus dengan banyak lingkaran arus akan mudah dilakukan penyesuaian.

Solusi transien yang akan ditentukan menyatakan keadaan sistem dekat dengan saat awal $t=0$ sehingga dalam hal ini metode deret Taylor-McLaurin menjadi sangat cocok untuk diterapkan. Besaran muatan listrik $Q(t)$ diperderetkan menjadi deret pangkat terhadap waktu dengan koefisien yang ditentukan dari nilai semua derivatif besaran itu pada saat awal. Dari persamaan (3) derivatif muatan sebagai fungsi waktu untuk orde 3 dan seterusnya dapat 
ditentukan secara berantai. Pekerjaan ini pada prinsipnya dapat langsung dilakukan secara manual namun akan sangat melelahkan sehingga harus dilakukan dengan bantuan komputasi simbolik. Dalam makalah ini digunakan bahasa REDUCE.

\section{BAHASA PEMROGRAMAN REDUCE}

Bahasa REDUCE merupakan satu di antara berbagai bahasa pemrograman simbolik yang tersedia di dunia komputasi. Bahasa ini sudah matang karena usianya yang sudah cukup panjang (saat ini sudah lebih dari 40 tahun) [7]. Bahasa ini semula merupakan komoditi komersial, namun sekarang sudah menjadi sumber yang terbuka (open source) [8].

Bahasa ini disusun oleh A.C. Hearns (seorang fisikawan) dan pada awalnya digunakan untuk komputasi dalam fisika partikel (yang menyangkut banyak sekali diagram Feynman). Dibandingkan dengan bahasa pemrograman simbolik yang lain, bahasa ini relatif kompak ditilik dari buku panduannya yang tidak terlalu panjang (kurang dari 300 halaman) [9]. Bahasa ini banyak juga digunakan dalam bidang keteknikan [10] dan sudah ada buku yang memberikan contoh penggunaannya secara eksplisit dalam hampir semua bidang fisika, mulai dari mekanika klasik sampai Teori Relativitas Umum dan Mekanika Kuantum [11].

Singkat kata bahasa REDUCE mempunyai kemampuan untuk mengolah bilangan bulat, bilangan rasional, bilangan tak rasional dengan ketelitian sangat tinggi dan simbol baik dalam bentuk umum (karakter) maupun ekspresi matematik. Berdasarkan berbagai pertimbangan itu maka bahasa REDUCE digunakan dalam makalah ini.

\section{HASIL DAN PEMBAHASAN}

Titik pangkal komputasi dalam persoalan ini adalah persamaan (3). Dengan memilih satuan komputasi yang sesuai maka koefisien-koefisien yang mengandung berbagai tetapan sistem dapat dibuat tak berdimensi. Untuk memudahkan pembahasan maka koefisien-koefisien itu dimisalkan mempunyai nilai tertentu berupa bilanganbilangan real. Demikian pula dicobakan nilai ggl yang gayut waktu secara sembarang.

Program dalam bahasa Reduce ternyata sangat singkat dan dapat dikutipkan sebagai berikut.

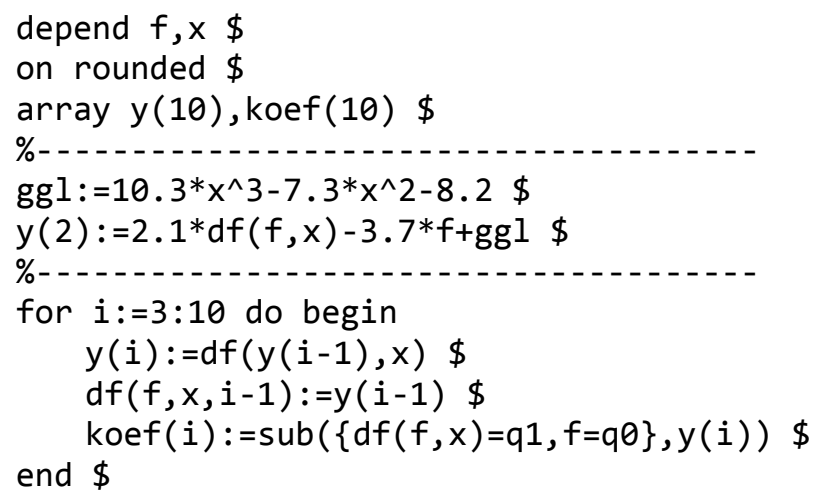

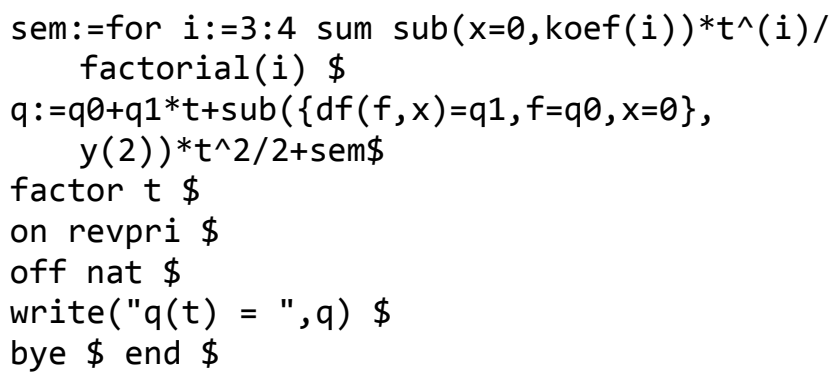

Untuk rangkaian tertentu maka program di atas dapat digunakan dengan mengganti dua baris yang dibatasi dua garis mendatar, yaitu untuk menyatakan persamaan (3) dan ggl yang gayut waktu (variabel $\mathrm{x}$ digunakan untuk menyatakan waktu dan muatan dinyatakan sebagai f).

Sedangkan keluaran dari program dapat dikutipkan sebagai berikut.

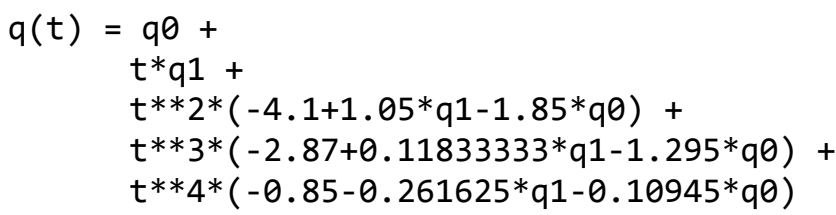

Sebagai contoh ditampilkan solusi sebagai polinom hanya sampai orde 4. Tentu saja dengan mudah kita akan dapat menentukan solusi itu sampai orde yang sangat tinggi. Dalam penyelesaian itu q0 dan q1 masing-masing menyatakan muatan dan arus pada keadaan awal. Notasinya mengikuti aturan notasi linear dengan tanda ** menyatakan pangkat.

\section{KESIMPULAN}

Komputasi merupakan bagian yang penting sekali dalam fisika. Komputasi merupakan jembatan antara fisika teori yang simbolik analitik (karena menggunakan matematika) dengan fisika eksperimental yang numerik (karena menggunakan pengukuran). Sebagai bidang yang mandiri komputasi bahkan sudah mempunyai landasan filosofi yang kuat [12].

Pemrograman merupakan implementasi dari metode komputasi. Meskipun pada hakikatnya semua bahasa pemrograman mempunyai ciri-ciri dasar yang sama [13], namun dalam praktek pemrograman yang mengikuti style dari pribadi pelakunya [14] akan timbul pilihan bagi pribadi yang bersangkutan.

Makalah ini memberikan contoh bahwa dengan menggunakan bahasa yang tepat maka akan bisa disusun program yang sangat pendek, kompak dan menghasilkan keluaran dalam bentuk yang diinginkan sesuai dengan tujuan komputasi. Di samping itu dengan pemilihan bahasa pemrograman yang sesuai secara pribadi dengan pelakunya maka aktivitas pemrograman itu akan menjadi sangat nikmat dan tidak saja bersifat ilmiah namun juga 
mengandung seni, sering disebut sebagai seni pemrograman (the art of programming).

\section{PUSTAKA}

[1] W.R. Smythe, Static and Dynamic Electricity, McGraw-Hill, 1950.

[2] C.R. Wylie, Advanced Engineering Mathematics, McGrawHill, 1975.

[3] P.G. Harper dan D.L. Weaire, Physical Mathematics, Cambridge University Press, 2008.

[4] E.R. Peck, Electricity and Magnetism, McGraw-Hill, 1953.

[5] A. Hermanto, Perbandingan Teori Relativitas dan Teori Kuantum : Relevansinya dengan Pengajaran S1 Fisika, Pertemuan Ilmiah HFI Jateng-DIY, Universitas Sudirman Purwokerto, 2011.

[6] A. Hermanto, Perhitungan Ralat Komputasi Gerak Benda Relativistik dalam Medium Penghambat dengan Metode Deret Taylor dan Bahasa UBASIC, Pertemuan Ilmiah HFI Jateng-DIY, IKIP Muhammadiyah Purworejo, 2012.

[7] A.C. Hearns, REDUCE : The First Forty Years, $A 3 L$ Conference, University of Heidelberg, 2005.
[8] W. Neun, REDUCE is Free Software as of January 2009, ACM Communications in Computer Algebra, vol. 43, 2009, pp. 15-16.

[9] A.C. Hearns, REDUCE User's Manual Version 3.8, 2004. Website : http://reduce-algebra.sourceforge.net, diakses tanggal 1 Januari 2013.

[10] N.I. Iokinidis, Finite Difference/Elements in Classical Beam Problems : Derivations of Feasibility Conditions under Parametric Inequality Constraints with the Help of REDUCE and REDLOG, Computational Mechanics, vol. 27, 2001, pp. 145-153.

[11] W. Heinzelman, Application-specific protocol architectures for wireless networks, Ph.D. dissertation, Massachusetts Institute of Technology, Cambridge, 2000.

[12] W.J. Rapaport, Philosophy of Computer Science, Teaching Philosophy, vol. 28, 2005, pp. 319-341.

[13] D.P. Friedman and M.Ward, Essentials of Programming Languages, MIT Press, 2008.

[14] P.W. Kernighan and R. Pike, The Practice of Programming, Addison-Wesley, 1999. 